SANTOS, Fernando Sergio Dumas dos; VERANI, Ana Carolina. Alcoolismo e medicina psiquiátrica no Brasil no início do século XX. História, Ciências, Saúde - Manguinhos, Rio de Janeiro, v.17, supl. 2, dez. 2010, p.401-420.

Resumo

Aborda o desenvolvimento da psiquiatria no Brasil, entre o final do século XIX e as três primeiras décadas do XX, com base no estudo da construção de saberes e práticas, neste campo, acerca do alcoolismo. Discute a visão da psiquiatria sobre a

\title{
Alcoolismo e medicina psiquiátrica no Brasil do início do século $\mathrm{XX}$
}

\section{Alcoholism and psychiatric medicine in early twentieth-century Brazil}

Fernando Sergio Dumas dos Santos Pesquisador da Casa de Oswaldo Cruz/ Fundação Oswaldo Cruz. Av. Brasil, 4036/s.406 21040-361 - Rio de Janeiro - RJ - Brasil fdumas@coc.fiocruz.br

\author{
Ana Carolina Verani \\ Professora da Rede Estadual de \\ Ensino do Rio de Janeiro. \\ Rua Itaperuna, 143 \\ 24240-070 - Niterói - Rio de Janeiro - Brasil \\ anacarolv@ig.com.br
}

Recebido para publicação em abril de 2010. Aprovado para publicação em setembro de 2010.

manifestação da loucura. Trata

hipótese de que o conceito de 'psicose alcoólica' buscou enfeixar os sintomas e problemas causados no indivíduo pelo alcoolismo crônico. Chama atenção para o fato de que esta era uma 'doença social', definição que a aproxima das classes populares: de seus costumes, práticas e condições de vida. Procura analisar as internações nos hospícios, recuperando os ecos das discussões médicas e tomando as reflexões do escritor Lima Barreto como contraponto ao saber médico da época.

Palavras-chave: alcoolismo; psiquiatria; história da medicina; Brasil; séculos XIX/XX.

\section{Abstract}

Based on a study of the construction of psychiatric knowledge and practices regarding alcoholism, the article explores the development of psychiatry in Brazil from the close of the nineteenth century through the first three decades of the twentieth. It examines both the role that psychiatry assigned to alcohol in manifestations of madness as well as the hypothesis that the concept of "alcoholic psychosis" was an attempt to encompass the symptoms and problems triggered within someone with chronic alcoholism. Defining the latter as a "social disease" tended to link it with the lower classes and their customs, practices, and living conditions. In an analysis of confinement to asylums, the article also captures echoes of the era's medical discussions and uses the reflections of writer Lima Barreto as a counterpoint to medical knowledge at that time.

Keywords: alcoholism; psychiatry; history of medicine; Brazil; nineteenth and twentieth centuries. 
$\mathrm{N}$ o Brasil, em princípios do século XX, uma das discussões sugeridas pela psiquiatria girava em torno da responsabilidade do álcool na manifestação da loucura: o álcool seria responsável pela produção dos sintomas de desordem mental ou a perturbação já existiria anteriormente, sob forma latente, e, nesse caso, o álcool funcionaria como um fator desencadeador de uma patologia já existente? Lima Barreto, que viveu na cidade do Rio de Janeiro entre os anos de 1881 e 1922 e passou por duas internações no Hospício Nacional de Alienados devido ao alcoolismo, também fazia a mesma indagação: "Houve quem perguntasse: bebemos porque já somos loucos ou ficamos loucos porque bebemos?" (Barreto, 1993, p.85). Naquele momento a psiquiatria estava se consolidando no Brasil como uma especialidade da medicina, institucionalizando-se como um saber específico sobre a loucura. Eram realizados estudos, pesquisas, produções acadêmicas e formulações teóricas que buscavam discutir as reflexões em torno da alienação mental.

Nesse contexto, o tema do alcoolismo esteve amplamente presente nos debates e produções médicas, tendo sido objeto de estudos e pesquisas de muitos psiquiatras. ${ }^{1} \mathrm{~A}$ associação entre alcoolismo e estados de demência, alcoolismo e moléstias mentais, era frequente, identificando o vício da bebida como responsável pelo surgimento da loucura em alguns indivíduos. Em alguns textos, publicados entre o final do século XIX e as primeiras décadas do XX, encontramos uma diferenciação entre a loucura denominada constitucional e a loucura alcoólica, sendo que esta última seria produzida (ou desencadeada) por uma intoxicação alcoólica e por isso foi incluída na categoria de 'psicose tóxica' (Santos, 1995; 2004).

Embora não houvesse consenso quanto ao fato de ser o alcoolismo causa ou consequência das moléstias mentais, não havia divergências na afirmação de que o abuso da bebida alcoólica era capaz de produzir sintomas praticamente iguais aos manifestados nos alienados mentais. No entanto, em muitos casos de alcoolismo, os sintomas desapareciam dentro de um determinado tempo, com a suspensão do uso do álcool, sendo então qualificados como transitórios. Mas havia casos de alcoólatras em que as desordens psíquicas poderiam permanecer, causando grandes transtornos para a vida desses indivíduos.

Ainda que a medicina tenha se preocupado com os danos que o excesso do álcool pode causar no organismo como um todo, como os problemas gastrointestinais e renais ou insuficiência hepática, o foco principal da psiquiatria eram os distúrbios mentais e os comprometimentos morais 'anormais'. Em um artigo de 1909, denominado "Psicoses alcoólicas", o médico Márcio Neri esclarece que o objetivo do seu texto é apresentar, resumidamente, "as devastações que sobre a mentalidade é capaz de exercer a intemperança alcoólica." Ele explica que dentro do termo "psicoses alcoólicas", foi encerrada "uma classe de desordens mentais duráveis, resultantes da intoxicação prolongada dos centros nervosos pelo álcool." Ainda segundo Neri:

Nesse agrupamento apontamos desde a tendência que o hábito faz surgir no organismo e que impele o indivíduo a procurar nas bebidas alcoólicas uma excitação que se tornou necessária e as vezes inelutável, até as lesões as mais graves do cérebro, do sistema nervoso em geral e de todo o organismo, que arrebatam, por completo, ao homem a sua mais nobre prerrogativa - a de um ser racional (Neri, 1909, p.339).

A constatação de que o uso abusivo do álcool provoca sinais e sintomas de loucura levou muitos médicos a especularem, então, sobre a origem de tais manifestações: 
São as psicoses alcoólicas devidas à intoxicação alcoólica? É talvez um contrasenso formular a dúvida. Mas, quando se consideram as várias formas pelas quais as desordens mentais se apresentam no alcoólico, tem-se o direito de interrogar se, no meio desses múltiplos acidentes, não há alguns ou muitos que corram por outras causas (Neri, 1909, p.347).

Márcio Neri observava que "a intemperança alcoólica põe às vezes em evidência paranoia ou constituições paranoicas que corriam despercebidas" (Neri, 1909, p.350). Seguindo este raciocínio, o álcool poderia ser tanto a causa das moléstias mentais, consideradas como manifestações de loucura causadas por intoxicação, quanto o desencadeador ou agravante de moléstias já existentes, mas não evidenciadas. Dentre os sintomas de distúrbios mentais apontados pelos médicos como característicos da intoxicação alcoólica estavam a mania, a melancolia, os delírios, as ideias e paranoias persecutórias, as alucinações auditivas e visuais, a desorientação e a confusão mental.

Em suas reflexões a respeito dos sintomas de loucura produzidos pelo efeito do excesso de álcool, Lima Barreto deixou registrado, em seu livro Diário de hospício: o cemitério dos vivos, a afirmação de que não era louco, mas que, ao mesmo tempo, admitia que seu alcoolismo algumas vezes o levara ao delírio: "Tenho certeza que não sou louco; mas devido ao álcool, misturado com toda a espécie de apreensões que as dificuldades de minha vida material, há seis anos, me assoberbam, de quando em quando dou sinais de loucura: deliro" (Barreto, 1993, p.153). ${ }^{2}$

\section{Doença orgânica ou hereditária}

A ideia da existência de uma predisposição orgânica inata a qual possibilitava o aparecimento das desordens mentais, defendida por muitos médicos, era fortemente influenciada pelas teorias científicas baseadas nos preceitos da hereditariedade e degenerescência formuladas por Auguste Morel. Juntamente com outros cientistas, como, por exemplo, Prosper Lucas - autor do Traité de l'heredité (Tratado de hereditariedade; 1850) -, Morel conferiu status de teoria às formulações referentes ao tema. Em seu Traité des dégénérescences physiques, intellectuelles et morales de l'espèce humaine, et des causes qui produisent ces variétés maladives (Tratado das degenerescências físicas, intelectuais e morais da espécie humana e das causas que produzem estas variedades doentias; 1857), Morel defendia que "as degenerescências são desvios doentios em relação ao tipo normal da humanidade, transmitida hereditariamente", e uma vez instalada a doença "ela segue seu curso e se transmite aos descendentes até a extinção da linhagem" (citado por Castel, 1978, p.259).

Dentro desta perspectiva, a predisposição poderia ser responsável tanto pela tendência individual de sucumbir ao vício da bebida - sendo neste caso o alcoolismo visto como consequência da constituição orgânica - quanto pela existência de distúrbios mentais que poderiam ser desencadeados ou agravados devido ao alcoolismo. $\mathrm{O}$ termo degenerado foi largamente usado pela medicina naquele momento, e dentro desta denominação se enquadravam aqueles que se tornavam alcoólatras por já serem degenerados e, portanto, já carregarem uma predisposição para a moléstia mental, sendo alienados 'em potencial':

Nos desequilibrados mentais, nos degenerados inferiores, o álcool exerce uma ação nociva. Lasègue afirmava que o álcool é a pedra de toque dos degenerados, fazendo 
alusão à ruptura de equilíbrio funcional do espírito ... Em indivíduos desta categoria podem presenciar-se esse casos de mania transitória, de fúria ebriosa, de impulsos agressivos, destruidores e perigosos, que rebentam de improviso ... Este é um episódio que se pode ver desenvolver-se nos fracos de espírito, nos imbecis e naqueles indivíduos que se acham sobrecarregados de vicio hereditário psicopático muito acentuado (Neri, 1909, p.348).

Outra característica da predisposição individual era a crença de que esta acarretava, para a mesma pessoa, sempre o mesmo tipo de embriaguez: um predisposto cuja característica da bebedeira fosse a alegria, por exemplo, teria sempre um temperamento alegre quando alcoolizado, independentemente de qualquer outro fator. A esse respeito, o doutor Nova afirma que:

É fato corrente na clínica dos manicômios que a embriaguez sempre se revela do mesmo modo em um determinado indivíduo: este será sempre tomado de alegria, aquele de tristeza veemente. É claro que não são ingeridas sempre as mesmas bebidas; ninguém faz excessos invariavelmente da mesma bebida, portanto é preciso procurar no próprio indivíduo a razão de ser dessa ação uniformemente fisiológica dos diferentes alcoólicos, e supor que eles todos, em bloco, reagem de modo tal que a natureza íntima desse indivíduo se revela (Nova, 1894, p.19-20).

Fatores hereditários, portanto, determinariam uma disposição mórbida que levaria ao excesso de álcool. Assim, em certos indivíduos, o hábito de beber apenas moderada e socialmente se transformaria em uma moléstia em que o costume se tornaria "uma necessidade orgânica", uma obsessão capaz de levar o sujeito a cometer atos insanos e descontrolados, a apresentar comportamentos condenáveis do ponto de vista moral e inadaptáveis socialmente:

Nos sujeitos predispostos esta necessidade adquire, às vezes, uma veemência verdadeiramente mórbida. A sede alcoólica exalta-se a tal grau que subjuga, domina, aniquila todas as outras funções psíquicas, que possam contrastar com esse desejo insaciado. É uma obsessão que se impõe de modo avassalante e que acorda impulsos irresistíveis e afecções dolorosas, enquanto o desejo não se sacia. Tão angustiosa é a situação moral deste individuo desequilibrado e tão irreprimível o impulso, que, para libertar-se da crise tremenda, ele não trepida nos meios de obter a bebida alcoólica. É preciso roubar? Matar? Desonrar-se para conseguir os seus fins? Ele o faz, o pobre dipsomaníaco (Neri, 1909, p.342).

A dipsomania foi outra resultante do processo de 'alienização' do alcoolismo. Esta entidade mórbida, fortemente vinculada às teorias da degeneração e da hereditariedade, caracterizava-se pela perda do controle do indivíduo sobre a própria vontade, isto é, uma impulsão irresistível tomava conta da pessoa, transformando-se em uma ideia hipertrofiada que sempre se transformava em ação. Segundo essa hipótese, o alcoólatra dipsômano era capaz de roubar, de matar, de deixar a própria família na miséria para satisfazer sua necessidade. Ele não seria permanentemente assolado por estes ataques, mas, como tinha suas capacidades volitivas bastante abaladas, as resoluções tomadas fora da crise nunca chegariam a se concretizar. A psiquiatria estabeleceu, então, uma distinção entre o 'alcoolista' e o 'dipsômano'. No primeiro caso, tratava-se de um indivíduo viciado, que sempre procurava companhia para beber, pois o problema dizia respeito à sua cultura, ao meio social em que vivia e à força dos exemplos. Já o dipsômano bebia sozinho, isolado, procurando, inclusive, 
esconder o seu ato. Para este, a incapacidade de manter o controle e a disciplina da vontade estavam no cerne da questão.

As explicações que atribuíam ao fator hereditário um componente determinante, fundamentadas na teoria da degenerescência, aparecem em um artigo escrito por Maurício de Medeiros, no qual ele afirma categoricamente não haver dúvidas sobre a "influencia nefasta do álcool" no que diz respeito às futuras gerações, atingindo os descendentes. Ele cita como exemplo uma família com o seguinte histórico:

Eram cinco filhos. Os dois primeiros muito fortes e sadios. O pai começa a beber e se embriaga frequentemente. Nasce um terceiro filho histérico e um quarto débil mental. $\mathrm{O}$ pai deixa de beber. Nasce um quinto filho sadio como os dois mais velhos. ... Indiscutível então é a degeneração dos filhos de alcoolistas inveterados (Medeiros, 1906, p.153).

Além disso, segundo o autor, os filhos dos alcoólatras não só apresentam moléstias mentais, mas também tendem a herdar o vício do álcool, e até a predileção por tal ou qual bebida: "Loeventin cita o caso de uma menina filha de um bebedor de absinto e que aos 6 anos manifestava gosto muito pronunciado por essa bebida" (Medeiros, 1906, p.154).

A questão da descendência dos alcoólatras impõe um foco estreito na figura da mulher. O conceito de hereditariedade vinha implícito na sua condição de mãe e a relação sexual era um ponto central. Assim, o ato sexual passou a ser visto como um meio que possibilitaria grandes chances à gestação destes seres de caráter deformado. Neste momento, não interessava somente a confissão de diferentes e nebulosas práticas do amor. O casal burguês, tido como o padrão de normalidade nesta sociedade, estava colocado em xeque, pois, dependendo das pessoas envolvidas, de seus hábitos e de sua educação, poderia vir a propagar o risco da degeneração. Esta era encontrada na sexualidade das figuras tradicionalmente estigmatizadas: os loucos, os criminosos, os doentes, os miseráveis. Segundo Charcot, "uma gota de esperma de um alcoólico contém toda a família nevropática" (citado em Lima, 1904, p.32). Mantendo a mesma lógica, os doutores Revoredo Barros e Alves Loureiro afirmavam que uma drástica diminuição dos nascimentos ocorrida em Londres, no ano de 1720, tinha na "bebedeira sua causa principal" (Loureiro, 1884, p.8; Barros, 1908, p.63).

O alcoolismo feminino despontou, neste contexto, como um episódio gravíssimo. Sob este prisma, as mulheres vinham descumprindo seu papel de ponto do equilíbrio moral e emocional da família, e, portanto, pilares da sociedade burguesa, sucumbindo ante os prazeres do álcool e faltando com seus deveres de mães. Segundo Barros, se a mulher, durante a gravidez, não se resguardasse da intemperança, os riscos e as consequências seriam imprevisíveis, pois "a tara é mais fatal e profunda se o alcoolismo congênito depende da progenitora" (Barros, 1908, p.54). De forma geral, era a fragilidade do organismo feminino que se destacava diante do álcool e do perigo da concepção dos filhos em estado de ebriedade, em função da hereditariedade das características degenerativas adquiridas. Também o risco da transmissão da 'tara alcoólica' pelo aleitamento materno era bastante ressaltado. O doutor Cunha Cruz fez alarde do perigo representado pelas mulheres alcoólatras, ao tratar do "problema do alcoolismo no Brasil". Para ele: 
é digno de atenção o número que indica a proporção de mulheres com perturbações mentais, devidas ao alcoolismo, em nossos hospícios e colônias. A proporção é tão grande, que difícil é encontrar igual em estatísticas, mesmo nos países mais alcoolizados - nós, pelo menos - não conhecemos igual (Cunha Cruz, 1906, p.14).

Outra evidência da importância dada ao hábito feminino de beber é a estatística acerca da família descendente da "ébria" Adda Jurke. Belisário Penna apresentou esta mulher como sendo ladra e vagabunda, além de bêbada. Este era um exemplo tão forte de degeneração moral, para esta sociedade, que sua família foi seguida e observada durante quase um século, e submetida a uma estranha contabilidade:

A ébria Adda Jurke teve 834 descendentes devidamente reconhecidos, dos quais cresceram 734, sendo que 142 viveram como mendigos, 108 nascidos de adultério, 64 viveram a custa da assistência pública, 181 mulheres prostituíram-se, 76 condenados por graves crimes, dos quais 7 assassinos, e durante 75 anos custou esta família, descendente da célebre Adda Jurke, ao Estado, seis milhões e um quarto de francos (Penna, 1921, p.18).

Seus vícios e seus crimes representavam a possibilidade da dissolução familiar, o que significaria, ao menos, uma forte rejeição à ordem capitalista. A marginalidade atribuída sujeitou-a a esta devassa de sua descendência. Por serem considerados anormais, seus parentes foram atentamente acompanhados pela ciência, que esperava, talvez, compreender o processo de transfiguração de seres humanos normais em bestas degeneradas. As práticas cotidianas, costumeiras em muitos setores das classes populares, e aquelas construídas em função de suas próprias experiências, vivenciadas nas ruas e nas franjas do sistema, passaram a ser comportamentos interpretados cientificamente. Assim, para muitos destes observadores, as leis da herança manifestar-se-iam inexoravelmente, independentemente de uma descendência proveniente de alcoólatras crônicos ou de bebedores de ocasião. Legrain foi um destes. Para ele o álcool era um elemento indicativo da herança nervosa, e os abusos que os indivíduos cometiam, seriam determinados por uma força oculta decorrente da herança (Nova, 1894, p.17-18). Se a intoxicação alcoólica fez-se presente no ato de concepção, a criança gerada estaria marcada pela degeneração para toda a vida. No dizer do doutor Araújo:

Os filhos que vingam aos alcoolistas estão sujeitos a convulsões, meningites, epilepsia (Legrain), e por idiotas, imbecis comiciais, vão para o hospício, mais dia, menos dia, pelo caminho da prisão (Afrânio Peixoto). As crianças que escapam a qualquer uma destas manifestações de heredoalcoolismo trazem, contudo, uma moral degradada, que o esforço da educação não pode suprimir. Todos têm uma tendência especial para se degenerarem. Tornam-se, bem cedo, onanistas ou pederastas ativos ou passivos e sentem-se felizes na sua degradação moral (Araújo, 1917, p.15).

A tentação da eugenia, que rondava as ciências ocidentais no final do século XIX, era sustentada, em grande parte, pelo mito da 'extinção da raça' - também aparecem nas fontes "extinção da prole" e "extinção da família" - através de sucessivas gerações de degenerados. De forma geral, o processo era entendido desta maneira:

Na primeira geração, manifestam-se a imoralidade, a depravação, os excessos alcoólicos e o embrutecimento moral; na segunda, tendência para o uso de bebidas alcoólicas, excessos maníacos, paralisia geral; na terceira, tendências hipocondríacas, lipemania, e as 
tendências homicidas; na quarta, enfim, a inteligência é pouco desenvolvida e a criança, estúpida ou idiota e degradada, atinge a idade adulta - e a raça se extingue (Cruveillier, citado por Barros, 1908, p.45).

Assim, quanto ao hábito de consumir bebidas alcoólicas, a psiquiatria pintava um quadro tenebroso, repleto de adjetivações negativas e que tinha no fim da espécie, o fechamento de um ciclo nefasto. Mas outros pontos de vista levantaram-se, em desacordo com as 'leis da herança', para usarmos um termo da época. Alguns médicos se perguntavam se uma criança, concebida em uma situação na qual o pai, embora fosse um alcoólatra crônico, não bebesse nada no dia da concepção da criança e a mãe observasse a mais completa abstinência durante a gravidez, carregaria "a lei da hereditariedade alcoólica". Eles argumentavam que, neste caso, o feto não deveria sofrer a influência do álcool em período algum da vida intrauterina. O doutor Revoredo Barros, por exemplo, indicava o francês Ladrague como um dos propugnadores desta vertente (Barros, 1908, p.51).

Fora do âmbito médico, iremos encontrar nos escritos de Lima Barreto críticas contundentes em relação à convicção científica quanto ao imperativo da hereditariedade. Em uma passagem do Diário do hospício, o personagem Vicente narra que, desde menino, tinha a ambição de "examinar a certeza da ciência", porque ao ler certo dia uma defesa de júri, encontrou na acusação do advogado a afirmação de que o réu era um irresponsável porque o "peso da tara paterna dominou todos os seus atos", tendo em vista que seu pai era um alcoólatra. O narrador, então um menino, questiona-se sobre aquela afirmação acusatória:

Demais, um vício que vem, em geral, pelo hábito individual, como pode de tal forma impressionar o aparelho da geração ..., até o ponto de determinar modificações transmissíveis pelas células próprias à fecundação? ... Não sabia responder isto e até hoje não sei responder, e ainda mais se me perguntava, nesse caso de alcoólico: no ato da geração, dado que fosse verdade essa sinistra teoria da herança de defeitos e vícios, o pai já seria deveras um alcoólico que tivesse as células fecundantes suficientemente modificadas, igualmente, para transmitir a sua desgraça ao filho? ... Menino, pouco lido nessa coisa, a afirmação daquele advogado de júri me pareceu menos certa do que se ele dissesse que um desvario, um mau gênio, tinha feito o seu constituinte errar, pecar, roubar ou assassinar (Barreto, 1993, p.101).

Para Lima Barreto, os médicos "procuram os antecedentes, para determinar a origem do paciente que está ali, como herdeiro de taras ancestrais; mas não há homem que não as tenha, e se elas determinam a loucura, a humanidade toda seria de loucos" (Barreto, 1993, p.40). Em outro momento do livro, mais uma vez o autor demonstra que não discordava quanto ao consenso médico de que o alcoolismo causava crises de loucura, mas questionava a exclusividade do álcool neste papel, perguntando se não seriam um conjunto de fatores que levariam à loucura, incluindo as mais diversas causas, inclusive as emocionais:

Essa questão do álcool, que me atinge, pois bebi muito e, como toda a gente, tenho que atribuir as minhas crises de loucura a ele, embora sabendo bem que ele não é o fator principal, acode-me refletir por que razão os médicos não encontram no amor, desde o mais baixo, mais carnal, até a sua forma mais elevada, desdobrando-se num verdadeiro misticismo, numa divinização do objeto amado; por que - pergunto eu - não é fator de loucura também? (Barreto, 1993, p.40). 


\section{Uma doença social}

A percepção de que o alcoolismo era uma doença social advinha da observação de que a doença não se restringia a problemas exclusivamente orgânicos, mas estendia-se para questões de ordem social e moral, já que os efeitos nocivos do álcool não se limitavam ao organismo do indivíduo, mas atingiam também o seu comportamento, abrangendo questões relacionadas à inserção dos indivíduos na sociedade industrial e repercutindo fortemente no mundo do trabalho capitalista, ainda em consolidação. Segundo a lógica científica dominante, ao se entregar ao vício da bebida, o indivíduo era corrompido, pois o abuso do álcool prejudicava o desempenho de suas funções na sociedade, podendo mesmo invalidá-lo por completo.

O conceito de doença social surgiu na Europa, na segunda metade do século XIX, quando a prática médica que se estabeleceu como dominante passou a perseguir maneiras de inventariar os hábitos cotidianos das pessoas e as suas práticas de vida, confrontandoos com as informações oriundas de outras disciplinas, tais como a química, a física e a história natural, buscando estabelecer os padrões de normalidade. Trazia consigo os valores morais constitutivos da ética do trabalho e aproximava-se 'naturalmente' das classes trabalhadoras e de seu cotidiano. Por volta de 1850, esse conceito já estava largamente difundido, abrangendo e criando moléstias derivadas do convívio social como a tuberculose, a sífilis, a loucura e o alcoolismo; doenças cujas tradições científicas consolidaram-se ao longo do processo de fazer-se do modo de produção capitalista.

$\mathrm{O}$ alcoolismo, sob este enfoque, era entendido como uma doença social e nisso, como bem observou Medeiros, consistiu a imensa dificuldade para a psiquiatria travar a luta contra tal doença, pois não se tratava de "uma questão simples de resolver", mas de "um complexo de problemas sociais, morais e científicos que a largos anos vêm preocupando as maiores inteligências humanas" (Medeiros, 1906, p.356). A ideia dominante no discurso médico do período era de que o vício da bebida levava o sujeito à ruína moral, apoderandose dele lenta e progressivamente. Assim, para Neri,

Na forma demencial, que é a de que nos propomos a falar, são justamente as aquisições mais altas da esfera moral as primeiras acometidas. Essa decadência dos sentimentos afetivos, embotando o respeito pela própria dignidade, relaxando os laços de família, tornando a sociedade um meio hostil, concorre para quebrar os freios que, porventura, ainda poderiam deter o intemperante em seus abusos alcoólicos. Mas o antagonismo entre o alcoólico e a família, cada vez se torna mais veemente (Neri, 1909, p.355).

A classificação de demência estava ligada a um enfraquecimento do espírito, a um estado no qual ocorria um embotamento das emoções e um descontrole das faculdades da vontade e intelectuais, e ainda às alterações comportamentais. $\mathrm{O}$ alcoolismo era entendido como uma moléstia capaz de afetar não apenas a organização psíquica do indivíduo, mas também a sua capacidade de convivência social e familiar, prejudicando ainda o desempenho no trabalho e consequentemente a sua produtividade, tornando-os incapazes para o cumprimento de seus deveres e responsabilidades. Segundo Neri,

As desordens éticas, por pouco que sejam alteradas, já se acompanham de mudança do caráter, que se torna irascível, violento e muitas vezes sombrio e desconfiado. A vontade, 
se algumas vezes resiste muito tempo, em regra é também precocemente alterada, diminuída. A indolência ou a falta de perseverança no trabalho, a ausência de energia para reprimir o vício, que ele percebe estar lhe causando a ruína da saúde e da economia, indicam claramente quanto se acha reduzida a força do querer (Neri, 1909, p.355).

Representativo da visão médica estabelecida na virada do século XIX para o XX no Brasil, este texto mostra o alcoólatra como um indivíduo levado a um estado tal de degradação, que passava a ser considerado um 'louco moral':

Não percebem que o ataque às mais nobres manifestações da esfera moral marca o primeiro passo que se desce na escala das degradações, que vai terminar na demência mais ou menos completa. ... O indivíduo que ficou privado ou que tem perturbada a manifestação desses nobres sentimentos, já é um louco e um louco moral, que é o mais nefasto à sociedade (Neri, 1909, p.356).

Esta preocupação não era uma característica exclusiva da medicina no Brasil. Ela evidenciava-se também em outros países da América Latina, como, por exemplo, na Argentina. Os médicos A. Jones e F.F. Morixe, do Hospício de Las Mercedes de Buenos Aires, concordavam com a interpretação dada aos efeitos do álcool em relação ao comportamento moral, pois, para eles, o doente crônico romperia com todas as regras sociais e com os laços familiares, chegando a ser associado a atos criminosos:

O alcoolista crônico, incapaz de outra coisa que não seja a mentira, recorre a todos os meios para satisfazer seus desejos, sempre intensos, de álcool; perde o pudor, a delicadeza; esquece todas as regras sociais, é negligente consigo mesmo, não se dedica à sua família, a sorte da sua esposa e dos seus filhos o deixam indiferente; os sentimentos de afeto se apagam; as súplicas e a miséria de seu lar não o comovem; suas expressões são grosseiras e sua linguagem, violenta. Nesse período o alcoolista pode se deixar levar pelos apetites mais ignóbeis, pelos crimes mais odiosos: o estupro, as violações, as tentativas de abuso contra as próprias filhas (Jones, Morixe, 1909, p.331; tradução livre).

Esta associação entre a alteração moral advinda do abuso alcoólico e o crime não era algo raro. Recorrendo aos escritos de Lombroso, o doutor Joaquim José da Nova deixounos um bom resumo das mazelas que, para os médicos, o hábito reiterado de usar e abusar das bebidas alcoólicas causava para a sociedade burguesa:

Segundo Lombroso, ele está em primeiro plano na etiologia do crime, pois, muitas vezes, antes de ser alienado, o alcoolista é o ladrão, é o assassino, é o coveiro da honra e do bemestar da família. Relativamente ao desperdício de energias preciosas para a riqueza econômica dos diversos países da Europa, não se pode desconhecer o papel importantíssimo do álcool. Para se fazer uma ideia das perdas enormes que acarreta o seu consumo, basta citar o cálculo de Laveleye relativamente à Inglaterra, onde os proletários, se renunciassem ao uso daquele líquido, poderão no espaço de vinte anos comprar todas as indústrias manufatureiras de que são simples assoldados (Nova, 1894, p.56).

A relação entre a loucura alcoólica e o crime era tão estreita, que, ao dividir o alcoolismo em três estágios (Santos, 1995; Santos, 2004), a medicina dava ao segundo o status de "período furibundo" ou "período do crime", no qual

o aspecto do ébrio tem algo de selvageria, de inexprimível ferocidade, que repugna, que apavora; o seu caráter transformou-se de alegre e expansivo que era, em turbulento e 
agressivo; o bêbado não tem mais um vislumbre de razão, é um inconsciente e impulsivo. É o estado em que o homem fica reduzido às condições de um irracional, capaz de tudo (Arantes, 1907, p.11-12).

Para Ruth Harris, foi dos hospícios e dos tribunais que saíram as principais contribuições para o desenvolvimento das teorias psiquiátricas acerca do alcoolismo, incluindo aí as principais observações clínicas (Harris, 1993). Destas observações nasceram inúmeras estatísticas: acerca do consumo de bebidas alcoólicas, do número de degenerados descendentes de alcoolistas, de acidentes de trabalho no dia seguinte ao repouso semanal por causa do uso de 'espirituosos', relacionando o aumento da criminalidade ao aumento do consumo de bebidas etc.

A sociedade burguesa foi pródiga em propor medidas judiciais que induzissem a uma diminuição do uso das bebidas alcoólicas, dentro de uma perspectiva que via o problema através do cruzamento dos pontos de vista médico-legais com os interesses do capitalismo em desenvolvimento. No que diz respeito à incorporação do tema do alcoolismo nos códigos penais, podemos citar como exemplo principal a Lei Seca, que vigorou por mais de dez anos nos Estados Unidos. ${ }^{3}$ Alguns códigos penais, como o do Reino ou o Sardo, este por volta de 1860, ambos na Itália, já reconheciam a embriaguez como figura jurídica (Santos, 1995). Segundo Arantes, na "Inglaterra as pessoas voluntariamente embriagadas são responsáveis por todos os crimes que cometeram neste estado" (Arantes, 1907, p.24).

O que estava em jogo nessas discussões, como se pode perceber, era o grau de responsabilidade do bêbado no momento em que cometeu o delito. As leis, no caso do alcoolismo, estiveram sempre aquém das expectativas e das pregações dos discursos médicos mais radicais, orientando-se para uma postura conciliadora que oscilava entre a força dos interesses morais e econômicos envolvidos e uma tradição costumeira de uso das bebidas, vinculada estritamente a uma sociabilidade essencialmente masculina e reforçada pelo princípio liberal da liberdade individual. A problemática do alcoolismo expandiu-se, assim, cada vez mais para a esfera social.

Outra noção que também foi bastante discutida no âmbito da medicina mental da época foi a de que o meio social poderia ser um fator capaz de despertar o alcoolismo. Assim, é possível observar, nas fontes analisadas, abordagens que consideravam os fatores sociais como certas condições de vida, hábitos, costumes - como capazes de exercer uma grande influência no sentido de contribuir largamente para o desenvolvimento do vício da bebida e de outras desordens mentais. Neste contexto, estas eram vistas não só como resultados de problemas orgânicos e hereditários, mas também como fruto da influência de certos meios e ambientes sociais, considerados inadequados, ou, ainda, de uma educação corrompida.

Em artigo intitulado "A paranoia e as síndromes paranoides", os médicos Juliano Moreira e Afrânio Peixoto, embora não tratem especificamente do tema alcoolismo, propiciam uma amostra da importância - e porque não dizer da atualidade - de tais elementos na discussão em torno do determinismo biológico ou social. Eles se posicionam de forma crítica em relação a uma tendência, vigorosa dentro do pensamento médico de então, de priorizar as determinações biológicas em detrimento das influências provocadas pelo meio social e, ao inverso desta corrente, defendem a valorização do meio social na explicação do 
desenvolvimento da paranoia: "Tenhamos, pois, a boa fé de procurar em nós principalmente no meio em que vivemos as causas de nossos males" (Moreira, Peixoto, 1905, p.9).

Em linhas gerais, os autores buscaram mostrar que o desenvolvimento da paranoia podia ser explicado devido a uma educação deficiente, que não funcionou no sentido de adaptar o indivíduo ao mundo, resultando em uma visão deturpada deste, em um desacordo profundo entre o paranoico e o mundo, fazendo com que este indivíduo se tornasse incapaz de se adaptar ao meio social e acreditando que é o mundo que deve se adaptar a ele, vivendo uma espécie de 'lesão da identidade social'. Assim, ainda que não neguem a teoria da degenerescência, Juliano Moreira e Afrânio Peixoto deixam claro que discordam quanto ao seu uso exagerado para explicar as doenças mentais:

Esta doutrina de degeneração, desde que se apresentou a Morel e veio nos tempos recentes se assenhorear da psiquiatria, não encontrou ainda senão submissões irrefletidas ... Longe de nós, seja dito logo, negar-lhe a verdade incontestável: ela existe, ela é profunda, a ela se deve grande parte de nossas misérias. Mas não é menos verdade que muito se tem abusado de sua fama, exagerando capitalmente a sua ação (Moreira, Peixoto, 1905, p.7).

Para estes psiquiatras não é possível desconsiderar "o meio em que vivemos uma vida inteira de combates e reacções incessantes, para tudo atribuir a umas tantas metafísicas da biologia" (Moreira, Peixoto, 1905, p.8). A noção de meio social que eles utilizam inclui a educação, a cultura e as regras sociais. Em seu artigo eles afirmam que:

Cada criança que nasce é socialmente comparável ao primeiro homem; o Eu lhe vem hipertrofiado, e, a julgar pela ampliação possível, sem as restrições modificadoras, cada uma seria comparável a um louco ou a um criminoso, é a educação, a disciplina, a cultura, que as submetem, modificam, adaptam; dando-lhes por fim essa identidade social (Moreira, Peixoto, 1905, p.8).

Cabe lembrar, no entanto, que as ressalvas feitas pelos médicos não fogem de todo ao amplo arcabouço teórico formulado por Morel. Se levarmos em conta que, apesar de a teoria da degenerescência ter tido enorme contribuição tanto na consolidação quanto na ampliação da perspectiva organicista e na ênfase dada à hereditariedade, ela também contribuiu para uma tendência que via a loucura como uma consequência de um desequilíbrio entre o individual e o social, "provocado por certos aspectos como os modos de vida desregrados, as conturbações políticas, a precariedade das condições de trabalho, a miséria, o fanatismo religioso" (Engel, 2001, p.132).

Morel buscou apresentar uma síntese que levava em conta, além da hereditariedade, o ambiente e o declínio social. Em suas próprias palavras: "Elaborei todo o livro a fim de ampliar o estudo das causas especiais da alienação, acrescentando nele, as causas de degenerescências intelectuais, físicas e morais da espécie humana" (Traité des dégénérescences citado por Castel, 1978, p.261). Esta formulação teórica exerceu uma notável influência na construção teórica da psiquiatria, possibilitando o alargamento tanto da definição de doença mental - ampliando as fronteiras do que era considerado patológico -, quanto da intervenção médica - e mais especificamente psiquiátrica - na sociedade. Se as causas das degenerescências não estavam mais restritas à esfera física, se a causa da alienação não era exclusivamente devida às lesões orgânicas, mas podia estar vinculada ao meio social, 
extrapolando o limite físico, cabia então à medicina se voltar para a sociedade e identificar os seus focos a fim de buscar uma intervenção visando a prevenção de sua disseminação. Segundo Morel:

Tudo nos leva a sair da falsa posição em que nos colocam, e a não permanecer como contempladores inativos de tantas causas destruidoras da espécie humana. Devemos provar que, qualquer que seja a dificuldade da situação, a medicina, longe de ser impotente ... pode ainda ... tornar-se para a sociedade um precioso meio de salvação. Somente ela pode, efetivamente, avaliar a natureza das causas que produzem as degenerescências na espécie humana, somente ela pode dar a indicação positiva dos remédios a serem empregados (citado por Castel, 1978, p.264).

Tal perspectiva, inserida no contexto de consolidação da psiquiatria como uma ciência específica dentro da medicina, contribuiu para a ampliação dos seus limites, determinando:

A incorporação de uma ampla variedade de temas na definição das fronteiras que separariam a 'doença' da 'saúde' no âmbito dos distúrbios mentais. ... Entre os temas privilegiados pelos alienistas e psiquiatras brasileiros na construção de atos, atitudes, hábitos, comportamentos, crenças e valores 'desviantes', figuravam, por exemplo, a civilização, a raça, a sexualidade, o trabalho, o alcoolismo, a delinquência/criminalidade, a contestação política (Engel, 1999, p.1).

A ideia de que o alcoolismo era uma moléstia, cuja problemática abrangia não só o âmbito médico, ganhava adeptos que se posicionavam no sentido de ampliar as discussões em torno do abuso do álcool para toda a sociedade, visando encontrar maneiras eficientes de combatê-lo. O alcoolismo era, portanto, um problema social, uma 'doença social'. Como afirmava Medeiros:

O alcoolismo sendo, como muito bem dizem quase todos os autores, um problema social, deve, como tal, sair do acanhado campo da ciência para ser debatido largamente por todos os que procuram de alguma forma o bem estar da Sociedade. Aliás não é o alcoolismo o primeiro a desertar das fileiras médicas para se alistar entre as sociais (Medeiros, 1906, p.149).

Esta constatação incidiu diretamente sobre as ações defendidas pelos médicos. Na prática, tais medidas se voltaram principalmente para aqueles indivíduos e ambientes que eram considerados degenerados em potencial, focos de disseminação: "Mas apesar da sociedade inteira estar no horizonte de uma intervenção preventiva, são evidentemente seus pontos fracos, os focos de desordem e de miséria, que serão prioritariamente visados" (citado por Castel, 1978, p.263).

As camadas mais pobres, as classes trabalhadoras, as pessoas que viviam de modo precário, por serem consideradas mais suscetíveis ao uso imoderado do álcool, representavam, então, a maior preocupação e o alvo principal das medidas de combate e prevenção. As precárias condições de vida a que estavam submetidas estas pessoas, principalmente nos ambientes urbanos, fragilizavam-nos frente à noção de epidemias o que facilitava a associação entre eles e a miséria urbana (Engels, 1985; Thompson, 1987). Discutindo a questão da importância do combate ao alcoolismo, Medeiros observou: 


\begin{abstract}
É preciso dogmatizar a luta contra o alcoolismo. É preciso que se difunda pelas classes operárias a noção precisa do perigo alcoólico, para que se possa depois exigir temperança. ... A falta de subsistência ... concorre para que o operário, sem o conhecimento exato do veneno que ingere, vá buscar no álcool um excitante, um fortificante graças ao qual ele possa atravessar essas largas 10 e 12 horas (Medeiros, 1906, p.49).
\end{abstract}

A problematização acerca do uso abusivo do álcool tinha o foco centrado na proposição de uma íntima relação entre o alcoolismo e os modos de vida das classes trabalhadoras. Para as classes dominantes, a medicalização dos costumes deveria preparar os indivíduos para as exigências advindas dos novos processos de trabalho capitalistas, atuando de forma a controlar costumes e práticas sociais e culturais. E o que parecia mais grave a estes olhos moralizadores era que o consumo de bebida andava sempre acompanhado de outros 'maus costumes': as serenatas com o violão; a frequência aos botequins e cabarés; as aglomerações e festejos populares; o barulho e as arruaças.

Havia, portanto, uma forte interferência de alguns destes costumes na disciplina do trabalho, como os aperitivos tomados antes e durante o expediente, as faltas e atrasos, além dos acidentes de trabalho, que eram largamente atribuídos ao uso e ao abuso do álcool. A sociedade consolidava uma tradição de uso das bebidas que formalizava e ritualizava uma busca de prazer localizada no limite das imposições ditadas pela normalidade burguesa. Porém, seus vínculos históricos com costumes pré-capitalistas estavam mantidos, e era por isso que esta tradição deveria ser definitivamente controlada e submetida à lógica do trabalho capitalista e, principalmente, afastada das classes trabalhadoras (Santos, 1995; Santos, 2006a; Santos, 2006b).

\title{
A reclusão no hospício
}

Se a 'prevenção' se daria através da propaganda, da educação e da censura, seguindo as bases dos princípios eugênicos que tiveram grande difusão no Brasil a partir dos anos 1910, o tratamento do alcoolismo se daria no hospício. Era através da internação que o doente, o alcoólatra, poderia ser resgatado para o convívio social. Michel Foucault, descrevendo cenas de meados do século XVII, relata-nos alguns casos de vagabundagem, mendicância e indigência, que eram tratados nas casas de internação. Esses termos genéricos, porém, já designavam, muitas vezes, o que as sociedades ocidentais vieram a classificar como embriaguez pública. Contudo, em sociedades onde prevaleciam os costumes comunitários como ordenadores dos modos de vida, apenas aqueles indivíduos estranhos a este convívio seriam internados (Foucault, 1989).

Por volta do último quartel do século XIX, acompanhando as transformações da cena urbana, a burguesia já tinha bastante definida para si a noção de privacidade, além de uma clara vivência das relações entre os espaços públicos e privados. Certamente, portanto, estas concepções foram transplantadas para o questionamento dos alcoólicos, gerando as figuras do bêbado vagabundo e do bêbado público - aquele que, por um motivo ou outro, não conseguiu "privatizar sua prática etílica" (Corbain, 1991, p.580).

As bebidas alcoólicas realçavam os elementos negativos da miséria, da indigência, da vagabundagem, e de outras figuras similares. O principal efeito sobre o homem, observado 
pela psiquiatria, era a liberação das paixões e dos traços de personalidade recessivos, ou que raramente apareciam. Todavia, estes não coadunavam com a vida numa coletividade de dezenas ou centenas de milhares de pessoas. E, embora desde muito tempo, a segregação social fosse a principal punição para aqueles que não se normalizavam, não se integravam aos modelos de comportamento dominantes, a participação da medicina científica neste processo deu outros contornos tanto aos problemas (miséria, vagabundagem, alcoolismo), quanto à solução da internação.

Tornara-se necessário, portanto, recorrer à verificação da marcha evolutiva dos sintomas e ao conjunto de informações que o médico conseguisse recolher a respeito do seu paciente - a chamada anamnese. Com o crescimento das ideias de hereditariedade alcoólica, muita gente teve seu diagnóstico confirmado a partir da presença de outros casos na família. Mas, ainda assim, não havia um consenso sobre estes procedimentos. Contudo, estes sintomas eram verificados, também, em pacientes que apresentavam outros tipos de doenças, o que levou os médicos a buscar um diagnóstico de tipo diferencial. Eles tentaram avançar analisando sintomas iguais ocorridos em patologias diferentes, com o fim de determinarlhes as características autônomas. Já não bastava a pessoa possuir todos ou vários, ou apenas um destes sinais para que fosse presumidamente um alcoólatra. A partir deste momento, seria preciso comparar os conjuntos de sintomas para identificar o alcoolismo, além disso:

\begin{abstract}
Nestas circunstâncias ainda, a sagacidade do médico deve ter em vista perscrutar o complexo de acidentes ou os mais insignificantes fenômenos que soem manifestar-se nos diversos aparelhos no decurso do alcoolismo crônico. ... Mas com isto as dúvidas não ficam resolvidas, e nem sempre encontra-se o caminho assim desbravado; o doente coisa alguma pode nos referir, o seu estado não o permite e os circunstantes se retraem; é um comatoso ou delirante que temos sob as vistas. Nestes casos o diagnóstico é muito complicado. No estado comatoso que figuramos, o coma pode ser urêmico e a uremia pode ser alcoólica. Se a supressão de um fluxo, natural ou patológico, o hemorroidário ou catamenial, por exemplo, podem explicar este fenômeno pela hemorragia; se as afecções reumáticas, sifilíticas e as degenerescências ateromatosas na velhice podem explicá-lo também pelos trombos, êmbolos, degenerescências vasculares, etc; outro tanto acontece com o alcoolismo em que todas estas lesões se observam (Loureiro, 1884).
\end{abstract}

Diante da falta de uma definição para o quadro de sintomas que possibilitasse um correto diagnóstico da doença, a terapêutica mais comum ficou sendo a tradicional receita popular: repouso, uma boa alimentação e abstinência das bebidas. Mas agora o lugar de curar o bêbado era o asilo, o hospício. E lá ele não contava mais com o café quente, tão comum no tratamento familiar. No Brasil do início do século XX, a consolidação da psiquiatria como campo de saber específico sobre a loucura levou a um aumento considerável de internações nos hospícios. Embora estas instituições tenham sido criadas ainda no Império, com o advento da República adquiriram uma nova característica: deixava de ser um espaço onde prevalecia a caridade e a assistência, para adquirir o caráter de instituição científica, redefinindo as práticas sociais relativas às doenças mentais. ${ }^{4}$

Durante o século XIX, já não era pequeno o número de internações psiquiátricas por alcoolismo no Brasil, chegando, por volta de 1860, a passar da metade do total de internos 
no Hospício de Pedro II (Macedo Jr., 1869, p.29), e fazendo com que este diagnóstico figurasse entre os primeiros nas estatísticas de internações. A preocupação com a superlotação que comprometia o tratamento e sua eficácia já estava explicitada em 1894, quando Teixeira Brandão afirmou que, como nos anos precedentes, a intoxicação alcoólica foi a principal causa determinante da alienação mental e, consequentemente, das internações no Hospício de Pedro II. Ele reafirmava a conveniência da criação de asilos correcionais para onde pudessem ser enviados os "alcoolistas de profissão quando as manifestações de loucura geradas pelo alcoolismo desaparecessem" (citado por Engel, 2001, p.289).

No mesmo sentido, na primeira década do século seguinte, Maurício de Medeiros apontava para uma aceleração deste processo, demonstrando sua preocupação com o enorme contingente de alcoólatras internados nos hospícios, e defendendo a criação de instituições específicas para eles, visando melhorar tanto o problema da lotação dos estabelecimentos psiquiátricos, quanto o problema das reinternações por alcoolismo, promovendo um tratamento mais direcionado e eficiente. Márcio Neri acreditava que um dos motivos para tantas reincidências se devia ao fato de não haver um local voltado exclusivamente para eles: "Há mesmo o caso notável de um indivíduo com vinte entradas. A explicação do fato está em não possuirmos ainda um serviço de assistência a alcoólicos, onde os relapsos do vício seguissem um tratamento adequado à sua condição" (Neri, 1909, p.355).

O modelo institucional e o tempo de internação dos alcoólatras tornaram-se questões bastante discutidas entre os psiquiatras: qual era o tempo realmente necessário para tratar (ou curar) o alcoolismo? Qual a necessidade de criação de instituições especiais, separadas dos hospícios, que abrigassem e tratassem os alcoólatras? Para Maurício de Medeiros, era preciso "antes de tudo" criar colônias de alcoolistas, "instituindo-se um sistema de recolhimento com trabalhos e diversões, que minorem o delírio e extingam o vício" (Medeiros, 1906, p.162). Márcio Neri, por sua vez, defendia que o isolamento do "delirante alcoólico" trazia o benefício de privá-lo "imediatamente das bebidas que foram causa da desordem mental", permitindo observar que, "após um lapso de tempo mais ou menos longo, segundo os casos, o delírio vai pouco a pouco desaparecendo até cessar completamente" (Neri, 1909, p.353).

Segundo sua análise, o alcoólatra não deveria receber alta tão logo desaparecessem os delírios, pois os distúrbios orgânicos continuariam ainda a debilitá-lo. O prolongamento da internação seria, assim, fundamental para que se evitassem as reinternações, pois era preciso suprimir as inflamações catarrais e do tubo gastrointestinal e as desordens hepáticas, que segundo ele eram a "causa que entretém a necessidade ou desejo de entregarem-se os intemperantes a novos abusos, para corrigirem as sensações indefinidas que interpretam como decorrentes da supressão do hábito" (Neri, 1909, p.354).

A partir de suas verificações e interpretações do processo nosológico, Neri chega a propor uma prescrição do tempo de internação necessário para curar estes doentes:

Seria muito mais útil para o indivíduo e para a sociedade ... prolongar a reclusão do alcoólico por três meses mais ou menos, afim de obter, além da cura do delírio, a correção do vicio alcoólico que se acha constituído no indivíduo e que vai certamente dar origem a recidivas e novas internações (Neri, 1909, p.354). 
É interessante notar que, no que diz respeito à prática psiquiátrica, havia um predomínio de uma concepção organicista relacionada à justificação da necessidade de um maior tempo de reclusão e isolamento. O próprio médico reconhece que a retenção prolongada é um "atentado à liberdade individual", tratando-se, porém, de "um atentado que só pode redundar em benefício do vicioso e da sociedade que o suporta" (Neri, 1909, p.354).

Dentro do hospício, as terapias incluíam os choques elétricos - usados para diagnosticar algumas perturbações dos nervos e para reativar as funções cerebrais - e as injeções de soro antialcoólico e de estricnina, esta para "excitar os centros medulares que regem as partes degeneradas" (Rangel, 1910; Santos, 1995). Havia certo reconhecimento de que o indivíduo que saísse da instituição asilar, mesmo que estivesse 'tratado' e 'curado', não seria facilmente reabsorvido pela sociedade. Este sujeito, estigmatizado pela internação, abatido pelos tratamentos, e, muitas vezes, desconfiado de si próprio e sem a confiança da família, raramente era incorporado à 'sociedade dos normais'.

E, nas classes populares, onde normalmente eram identificados estes casos, as precárias condições de moradia e de vida possivelmente levariam estas pessoas de volta ao asilo onde, muitas vezes, era o único lugar em que elas teriam uma refeição garantida e onde havia quem cuidasse delas, fosse da maneira que fosse. Para os médicos em geral, era o próprio bêbado, e só ele, o responsável por esta situação. O doutor Antônio Loureiro tinha uma visão até certo ponto cética sobre o processo terapêutico a que eram submetidos os alcoólatras:

Se as psicopatias alcoólicas em seus períodos de média intensidade podem ser curadas instantaneamente, quase que exclusivamente pelo método gradual de abstenção; se seu prognóstico pode ser relativamente favorável em muitos casos, a desilusão não tardará. O alcoolista tira-nos todas as perspectivas, ele tem a fascinação do abismo; uma vez lançado na voragem do vício, vai até ao fim na maioria dos casos. É pueril contar com o retrocesso. As psicopatias de ordinário marcham para os últimos limites dos seus domínios. Como exemplo, citamos o que se passa nos hospícios, que os alcoolistas alienados frequentam com intervalos variáveis, que representam as curas obtidas, até que a morte sobrevenha, seja procurada pelo suicídio ou a demência os desequilibre na sociedade (Loureiro, 1884, p.77).

\section{Um outro olhar}

Lima Barreto deixou-nos um importante testemunho de quem viveu a experiência de internação e fez questão de refletir e escrever sobre ela, contribuindo para a possibilidade de se analisar estas questões sob outro enfoque. Profundo conhecedor da alma, dos desejos e do cotidiano das classes populares, o escritor expôs suas reflexões e críticas sobre a loucura de modo geral, sobre a sua própria doença e sobre questões relativas à instituição psiquiátrica, aos saberes e às práticas médicas. Ele não discordava da necessidade de suas internações, nem negava os efeitos nocivos causados pelo cotidiano abuso do álcool. Reconhecia que esses hábitos teriam causado suas manifestações de loucura:

Quando, pela primeira vez me recolheram ao Hospício, de fato a minha crise era profunda e exigia o meu afastamento do meio que me era habitual, para varrer do meu espírito as alucinações que o álcool e outros fatores lhe tinham trazido. 
Foi aí que eu vi bem o mal da 'bebida' ... De quando em quando, provocava-me alucinações, eu incomodava os outros, metiam-me em casas de saúde ou no Hospício, eu renascia, voltava, e assim levava uma vida insegura, desgostosa e desgostando os outros (Barreto, 1993, p.123).

Contudo, o que ele questionava era a submissão a que se achava relegado frente ao poder do médico, fato que a sua condição de doente o obrigava. Colocava, assim, em discussão as formas de compreender e lidar com as doenças mentais e os alienados. Uma vez dentro do hospício, os internos perdiam o direito de decidir sobre suas vidas, sobre si mesmos, ficando entregues ao poder outorgado aos médicos pela sociedade moderna. Analisando seu encontro com um médico do hospício, ele escreveu:

Essa sua falta de método, junto a minha condição de desgraçado, davam-me o temor de que ele quisesse experimentar em mim um processo novo de curar alcoolismo em que se empregasse uma operação melindrosa e perigosa. Pela primeira vez, fundamentalmente, eu senti a desgraça e o desgraçado. Tinha perdido toda a proteção social, todo o direito sobre o meu próprio corpo, era assim como um cadáver de anfiteatro de anatomia (Barreto, 1993, p.175).

Lima Barreto usa o medo de se transformar em um 'magnífico campo' para novas experiências, para criticar o que considerava como uma tendência ao abuso da autoridade médica, fundamentada em certezas científicas que também eram alvo de críticas do escritor, pois, para ele, nenhuma das teorias existentes dava conta de uma explicação para a loucura:

Faziam-me perguntas de confessor, e eu as respondia com toda a veracidade de catecúmeno obediente; mas, no meu íntimo, eu tinha para mim que tudo aquilo era inútil. Há uma classificação, segundo este ou aquele; há uma terminologia sábia; há descrições argutas de tais e quais casos, revelando pacientes observações; mas uma explicação da loucura, científica, atribuída a falta ou desarranjo de tal ou qual elemento ou órgão da nossa natureza, parece que só há para raros casos, se há (Barreto, 1993, p.173).

Assim, os médicos deveriam se voltar mais para a análise da realidade de cada caso, separadamente, livres de julgamentos a priori, ao invés de apenas generalizarem a partir de teorias científicas, acreditando na sua absoluta certeza e reduzindo o doente a um objeto de investigação (Verani, 2003, p.93).

Além disso, as ideias negativas divulgadas em torno do alcoólatra contribuíam para que este fosse identificado como perigoso, associado a um mal da sociedade, sem nenhuma utilidade. Tal visão, segundo ele, acabava por contribuir para uma percepção coletiva que enquadrava todos os alcoólatras na classificação de periculosidade, justificando a truculência com que eram tratados, principalmente aqueles que eram levados ao hospício pelas mãos da polícia:

O médico tem em sua frente um doente de que a polícia é tutor e a impersonalidade da lei, curador, por melhor que seja, não o tem mais na conta de gente, é um náufrago, um rebotalho da sociedade, a sua infelicidade e desgraça podem ainda ser úteis à salvação dos outros, e a sua teima em não querer prestar esse serviço aparece aos olhos do facultativo, como a revolta de um detento (Barreto, 1993, p.174).

Marcado pela experiência pessoal de já ter sido transportado ao hospício dentro de um carro-forte, o autor revela que não poderia haver coisa pior, e que a humilhação e o sofrimento 
por que se passa não poderiam ser benéficos para o indivíduo: "Um suplício destes, a que não sujeita a polícia os mais repugnantes e desalmados criminosos, entretanto, ela aplica a um desgraçado que teve a infelicidade de ensandecer, às vezes, por minutos..." (Barreto, 1993, p.22).

\section{Considerações finais}

Como diz Maria Clementina Pereira da Cunha, ao comentar a história do Hospício do Juquery:

Até o final do século XIX, as práticas destinadas ao controle da loucura caracterizavamse claramente como simples mecanismos de exclusão social, voltadas para loucos 'furiosos' ou 'perigosos', cuja detenção podia prescindir da lógica médica. O lugar da loucura reclusa podia ser a cadeia, a Santa Casa, a Casa de Correção, mesmo depois do advento dos hospícios (Cunha, 1986, p.58).

Em princípios do século XX, parte dos médicos já considerava o alcoolismo como uma doença dos nervos, ou uma nevropatia. Ele passou a ser conhecido como uma nevrite, com o sufixo 'ite' indicando uma inflamação, uma infecção dos nervos. O termo não era propriamente novo, mas a compatibilidade desta designação com a teoria pasteuriana, o principal paradigma científico do período, viabilizou a sua maior aceitação. A nevrite alcoólica evoluíra de uma concepção de 'monomania' - que vigorou no século passado para uma visão de multiplicidade, que a associou a diversas 'manias', tais como a 'alcoolomania' de Dromard, ou os "acessos de loucura em forma de mania aguda" descritos por Kraft-Ebing (Lima, 1904; Morais, 1890). As múltiplas lesões identificadas ao problema transformavam-no, muitas vezes em polinevrites.

Aqui no Brasil, o médico Eurico Rangel observara uma predominância da incidência da nevrite alcoólica sobre os indivíduos do sexo masculino, fato que, para ele, "mantém direta correlação com os hábitos e costumes dos habitantes" (Rangel, 1910, p.10). Todavia, verificamos que este mesmo médico diagnosticou, em um doente a polinevrite alcoólica, e em outro o alcoolismo. Ele descreveu praticamente os mesmos sintomas para os dois, sendo que aquele cuja motilidade estava mais afetada foi apontado como possuidor da polinevrite, apesar de que os problemas com o aparelho locomotor estivessem tradicionalmente vinculados ao alcoolismo. Em contrapartida, o paciente no qual foi diagnosticado o alcoolismo tinha uma movimentação perfeita.

Mas, em 1890, o doutor Rodrigues de Morais já tivera a preocupação de apontar a mudança pela qual passou a concepção de doença mental também no nosso país. Seu interessante depoimento, rico em metáforas, enfatizava as possibilidades de cura:

As moléstias mentais não representam mais aquele proteu que revestia mil formas, elas são estudadas e classificadas de um modo consciencioso, as leis e princípios que as regem são perfeitamente estabelecidos. Os gritos estridentes dos maníacos, o riso histérico das infelizes que povoam os hospícios e as contrações dos epiléticos não mais requerem as algemas e as cadeias de outrora para serem dominados: a terapêutica hodierna fornece meios de se realizar esse desideratum (Morais, 1890, p.2). 
É claro que toda essa fé na positividade dos preceitos científicos e, especialmente, psiquiátricos, no Brasil da última década do século passado, carecia de uma prática clínica e fundamentalmente política que a embasasse. Mas era significativa, se pensarmos no processo histórico que se desenvolvia aqui. O positivismo, a ciência e a modernidade podem ser considerados três símbolos da recém-nascida República, não importando muito, neste sentido, que as práticas não correspondessem aos ideais.

\section{NOTAS}

${ }^{1} \mathrm{O}$ termo alcoolismo foi criado pelo médico sueco Magnus Huss, em 1849, e apresentado no artigo "Alcoholismus chronicus, eller chronisk alkoholsjukdom; ett bidrag till dyskrasiernas Kännedom, enligt egen och andras erfarenhet". Esta foi a primeira vez em que o conceito de alcoolismo foi utilizado para designar o conjunto de lesões e fenômenos produzidos pelo largo consumo de bebidas alcoólicas.

${ }^{2}$ Neste livro estão reunidos dois textos de Lima Barreto: o primeiro combina memórias e reflexões acerca da vida no manicômio, e foi escrito em forma de diário durante a permanência do escritor no Hospital Nacional de Alienados. O segundo, escrito com base nas observações do diário, mistura aspectos reais com ficcionais, consistindo numa espécie de rascunho para um romance que não foi concluído.

${ }^{3}$ Em 1919 foi editada nos Estados Unidos a famigerada Lei Seca: a lei que proibiu o fabrico, o transporte e a comercialização de qualquer bebida alcoólica em todo o país. O governo norte-americano foi exaltado, em sua coragem e firmeza, pelos que pleiteavam mais rigor do governo brasileiro a esse respeito; aquele era o comportamento a ser seguido. O sentido desta lei repousava na articulação entre um projeto de Estado que visava o estabelecimento de uma economia pragmática, e um projeto dos setores de ponta da indústria norte-americana, capitaneados por Henry Ford, que visava aperfeiçoar os métodos do trabalho capitalista. A formação de um "novo tipo de trabalhador conforme a indústria fordizada exigia" pressupunha novos hábitos e novas representações dos sinais vitais do mundo. A moral protestante era o instrumento ideal para estas transformações, já que sua verve religiosa falava alto ao imaginário popular nos Estados Unidos e na Europa, e as práticas de vida adotadas pelos seguidores destes cultos adequavam-se sobremaneira às ansiedades das elites capitalistas. Sobre o 'trabalhador fordizado' ver Gramsci (1984).

${ }^{4}$ O primeiro hospital psiquiátrico foi criado no Brasil durante a Monarquia e inaugurado em 1852 com o nome Hospício de Pedro II. Porém a sua existência, diferentemente de alguns exemplos europeus, não esteve logo de início ligada à exclusividade de um saber médico sobre a loucura. A administração do hospital permaneceu subordinada à Santa Casa de Misericórdia até o início da República, quando foi transformado no Hospício Nacional de Alienados.

\section{REFERÊNCIAS}

ARANTES, José Augusto.

A embriaguez. Tese apresentada à Faculdade de Medicina do Rio de Janeiro, Rio de Janeiro. 1907.

ARAÚJO, Guilherme Vítor de.

D'ação do álcool e do fumo sobre o nervo optico. Tese apresentada à Faculdade de Medicina do Rio de Janeiro, Rio de Janeiro. 1917.

BARRETO, A.H. Lima.

Diário do hospício: o cemitério dos vivos. Rio de Janeiro: Secretaria Municipal de Cultura. 1993.

BARROS, Galeno de Revoredo.

Do alcoolismo na infância sob o duplo ponto de vista clínico e social. Tese apresentada à Faculdade de Medicina do Rio de Janeiro, Rio de Janeiro. 1908.
CASTEL, Robert.

A ordem psiquiátrica: a idade de ouro do alienismo. Rio de Janeiro: Graal. 1978.

CORBAIN, Alain.

Gritos e cochichos. In: Perrot, Michelle (Dir.) História da vida privada, v.4: da Revolução Francesa à Primeira Guerra. São Paulo: Companhia das Letras. 1991

CUNHA, Maria Clementina Pereira da. O espelho do mundo: Juquery, a história de um asilo. Rio de Janeiro: Paz e Terra. 1986.

\section{CUNHA CRUZ.}

O problema do alcoolismo no Brasil: apelo aos Exmos. Snrs. representantes do poder público e à imprensa no Brasil. Rio de Janeiro:

Typographia do Jornal do Commercio. 1906. 
ENGEL, Magali.

Os delírios da razão: médicos, loucos e hospícios (Rio de Janeiro, 1830-1930). Rio de Janeiro: Editora Fiocruz. 2001.

ENGEL, Magali.

As fronteiras da 'anormalidade': psiquiatria e controle social. História, Ciências, Saúde Manguinhos. Rio de Janeiro, v.5, n.3. p.547-563. 1999.

ENGELS, Friedrich.

A situação da classe trabalhadora na Inglatera. São Paulo: Global. 1985.

FOUCAULT, Michel.

História da loucura. São Paulo: Perspectiva. 1989.

GRAMSCI, A.

Maquiavel, a política e o Estado moderno. Rio de Janeiro: Civilização Brasileira. 1984.

HARRIS, Ruth.

Assassinato e loucura: medicina, leis e sociedade no fin de siècle. Rio de Janeiro: Rocco. 1993.

JONES, A.; MORIXE, F.F.

Psicosis alcoholicas. Rio de Janeiro, Archivos Brasileiros de Psychiatria, Neurologia e Medicina Legal, n.3-4. 1909.

LIMA, Joaquim Ferreira dos Santos. Que regras devem dirigir o uso das bebidas fermentadas e destiladas na cidade do Rio de Janeiro. Tese apresentada à Faculdade de Medicina do Rio de Janeiro, Rio de Janeiro. 1862.

LIMA, Manoel Cintra Barbosa.

Alcoolismo hereditário. Tese apresentada à Faculdade de Medicina do Rio de Janeiro, Rio de Janeiro. 1904.

LOUREIRO, Antônio Alves.

Do alcoolismo crônico e suas consequências.

Tese apresentada à Faculdade de Medicina do Rio de Janeiro, Rio de Janeiro. 1884.

MACEDO JR., João Álvares de.

Da prostituição no Rio de Janeiro e da sua influência sobre a saúde pública. Tese apresentada à Faculdade de Medicina do Rio de Janeiro, Rio de Janeiro. 1869.

MEDEIROS, Maurício de.

Notas de um antialcoolista. Rio de Janeiro: Archivos Brasileiros de Psychiatria, Neurologia e Sciencias Affins, n.2. 1906.

MORAIS, Jerônimo Rodrigues.

Psicoses de origem tóxica. Tese apresentada à
Faculdade de Medicina do Rio de Janeiro, Rio de Janeiro. 1890.

MOREIRA, J.; PEIXOTO, A.

A paranoia e os syndromas paranoides.

Archivos Brasileiros de Psychiatria, Neurologia e

Sciencias Affins, v.1, n.1, p.5-33. 1905.

NERI, Márcio.

Psychoses alcoólicas. Rio de Janeiro, Archivos Brasileiros de Psychiatria, Neurologia e Medicina Legal, n.3-4, 1909.

NOVA, Joaquim José da.

Capacidade civil dos alcoolistas. Tese apresentada à Faculdade de Medicina do Rio de Janeiro, Rio de Janeiro. 1894.

PENNA, Belisário.

O demônio da humanidade. Rio de Janeiro: Casa Publicadora Batista. 1921.

RANGEL, Eurico.

Da nevrite alcoólica. Tese apresentada à

Faculdade de Medicina do Rio de Janeiro, Rio de Janeiro. 1910.

SANTOS, Fernando S. Dumas dos.

Bêbados e alcoólatras, medicina e cotidiano. In: Nascimento, D. R; Maul, D. Uma história brasileira de doenças. v.2. Rio de Janeiro: Mauad, p.64-91. 2006a.

SANTOS, Fernando S. Dumas dos.

Moderação e excesso; uso e abuso: os saberes médicos acerca das bebidas alcoólicas. Clio Revista de Pesquisa Histórica. v.2, p.29-48. 2006b.

SANTOS, Fernando S. Dumas dos.

A construção do alcoolismo no conhecimento médico. In: Nascimento, D. R; Maul, D. Uma história brasileira das doenças. Brasília: Paralelo 15. p.308-322. 2004.

SANTOS, Fernando S. Dumas dos.

Alcoolismo: a invenção de uma doença.

Dissertação (Mestrado) - Universidade Estadual de Campinas, Campinas. 1995.

THOMPSON, Edward P.

A formação da classe operária inglesa. $3 \mathrm{v}$. Rio de Janeiro: Paz e Terra. 1987.

VERANI, Ana Carolina.

O triste fim de Lima Barreto: literatura, loucura e sociedade no Brasil da belle époque. Dissertação (Mestrado) - Pontifícia Universidade Católica do Rio de Janeiro, Rio de Janeiro. 2003.

\section{$\rightarrow \rightarrow \rightarrow<<<$}

